Trends Pharmacol Sci. 2006 November ; 27(11): 574-579. doi:10.1016/j.tips.2006.09.007.

\title{
The schizophrenic faces of PICK1
}

\author{
Kumlesh K. Dev ${ }^{1}$ and Jeremy M. Henley ${ }^{2}$
}

${ }^{1}$ Neuroscience Research, Novartis Institutes for BioMedical Research, Novartis Pharma, WSJ 386-7-43, Lichtstrasse 35, CH-4056 Basel, Switzerland 2MRC Centre for Synaptic Plasticity, Department of Anatomy, School of Medical Sciences, University Walk, University of Bristol, Bristol BS8 1TD, UK

\begin{abstract}
Schizophrenia is a grave psychiatric disorder with psychotic symptoms and an enigmatic etiology. Family studies have strongly indicated that genetic risk factors have a role in this disease. Recent findings, together with previously established evidence, highlight the PDZ-domain-containing protein interacting with C-kinase 1 (PICK1) as a promising candidate for a schizophrenia susceptibility gene. Here, we outline possible molecular mechanisms, discuss clinical case-studies that indicate an unexpected role of PICK1 in schizophrenia and discuss potential avenues for pharmacological manipulation of PICK1.
\end{abstract}

\section{Introduction}

Schizophrenia is a severe brain disease that triggers positive and negative symptoms, including psychotic characteristics such as hallucinations, delusions and paranoia (see Glossary), cognitive impairment, loss of motivation and impaired ability to manage emotions and relationships [1,2]. The illness presents in several forms, which are diagnosed based on specific symptoms, the most common being paranoia. Schizophrenia occurs in almost $1 \%$ of the US population and emerges earlier in men (teens to 25 years of age) than in women (ages 25-35), with an estimated 2.2 million Americans affected each year. Genetic association, viral infection, brain injury and drug abuse during embryonic brain development have all been associated with the etiology of this disease [1-4].

Schizophrenia is not linked to a solitary genetic mutation and probably involves a heterogeneous mechanism with polymorphisms in several genes and in a range of environmental susceptibility factors [3-8]. Individually, these abnormalities probably have sub-threshold effects that can be difficult to confirm in genetic studies but, in combination, might manifest in symptoms [5-8]. These genetic and environmental factors result in a complex pathophysiology that includes: (i) problems in brain development and the aberrant formation of neuronal circuits; (ii) abnormal regulation of neurotransmitter concentrations and receptor activity; (iii) defects in metabolic pathways and enzyme function; and (iv) reduced brain volumes that are probably coupled with neurotoxicity and neurodegeneration [4-8]. Some of the genetic, pharmacological and environmental evidence that has inferred risk factors for schizophrenia is described in Box 1. The diversity in origin connected to this illness provides potential for several therapies that could correct receptor and enzyme function, repair neuronal circuits and prevent the progress of neurodegeneration. Better understanding of the molecular mechanisms that underlie schizophrenia will improve the 
ability to stratify patients, make tailored drugs and improve therapeutic outcomes. Therefore, the continued discovery of novel genes that are involved in this disorder remains crucial for developing better drugs.

Protein interacting with C-kinase 1 (PICK1) is a recently proposed candidate protein for involvement in schizophrenia $[9,10]$. The pick 1 gene is located on chromosome 22q13.1, which is a genetic locus that frequently links to schizophrenia [8,11-13]. At the protein level, PICK1 has been studied extensively because of its role in regulating the cell biology and functional properties of several important neuronal proteins [14-16]. PICK1 is a scaffolding protein that is located at neuronal synapses and associates with a wide range of proteins via its functional domains, which include a PSD95-Disc-large-ZO-1 (PDZ) domain and a Binamphiphysin-Rvs (BAR) domain [14]. PICK1 interacts with protein kinase $\mathrm{C}$ (PKC) and regulates the phosphorylation of many PICK1-interacting partners, thereby altering their synaptic clustering, trafficking to the neuronal surface and membrane recycling. A search for convergent loci has located not only PICK1 but also many of its interacting proteins, including neuregulin receptors, glutamate receptors and ephrins, within linkageregions of schizophrenia [8]. The proteins with an accepted association with schizophrenia and their interaction with PICK1 are described in Box 1.

Interest in PICK1 has been heightened by three recent genetic studies that investigated a role for this protein in schizophrenia. The first of these case studies involved the examination of 225 schizophrenic and 260 control Han Chinese patients. It revealed an association between a single nucleotide polymorphism (SNP), rs3952 in intron 3 of pick1, and the diagnosis of schizophrenia [11]. A second case-study of 200 unrelated Japanese schizophrenic patients and 200 age-matched Japanese normal controls found an association between an SNP, rs2076369 in intron 4 of pick1, and schizophrenia but only when using 'disorganized' schizophrenics [12]. Associations of lower magnitude might be expected if disease susceptibility results from the combined effect of several variants in a gene. Significantly, both of the SNPs reported occurred in the PDZ domain of PICK1, with no evidence of SNPs in the BAR domain (Figure 1). A third study comparing elderly schizophrenia patients (36 patients) with matched normal controls (26 patients) showed no difference in levels of PICK1 mRNA in the occipital cortex of elderly schizophrenia patients compared with matched normal controls [13]. This observation leaves open the possibility that PICK1 SNPs are more crucial for regulating the function of the PDZ domain than are total mRNA or protein levels. Although these genetic findings are potentially important, they require evidence from a larger population to confirm that mutations in PICK1 are associated risk factors for schizophrenia.

Further evidence of a role for PICK1 in schizophrenia comes from the proteins with which it interacts that have been associated with the illness (Figure 1) and there are different possible approaches to regulating these interactions (see later). Overall, collating evidence from genetic and protein interaction studies, we believe that one underlying biological cause of increased susceptibility for schizophrenia is the altered interactions between PICK1 and its associated synaptic proteins.

\section{Functional domains of PICK1}

PICK1 is 416 amino acids in length and has a single PDZ domain [14] (Figure 1). This domain contains $\sim 90$ residues and interacts with proteins that harbor PDZ-binding motifs at their C-termini. The PDZ domain of PICK1 accepts a range of PDZ-binding motifs and, thus, mediates protein-protein interactions with many different proteins [14]. PICK1 also has a sequence homology to the BAR domain of arfaptin2 [17-19]. BAR domains, which are present in many GTPases and other proteins, are involved in endocytosis. They are coiled- 
coil structures that dimerize to form banana-shaped structures that bind to phospholipids, sense and/or promote membrane curvature and promote endocytosis [17-19] (Figure 1). The two coiled-coil regions of a single PICK1 protein can dimerize and, following binding to its PDZ receptor or transporter, PICK1 dimers can target the receptor-transporter complexes to membrane areas in which endocytosis can occur [20,21]. Thus, via its BAR domain, PICK1 can direct PDZ-interacting proteins that are destined for internalization to membrane invaginations such as clathrin-coated pits. PICK1 is also a $\mathrm{Ca}^{2+}$-sensing protein - consistent with an active role in endocytosis and exocytosis, which are $\mathrm{Ca}^{2+}$ dependent [22]. When the PDZ domain is unoccupied, autodimerization of the PICK1 BAR domain can be inhibited by an intramolecular interaction with its own N-terminal PDZ domain [23]. Thus, the PICK1-mediated recruitment of PKCa can lead to phosphorylation of its interacting partners - which, together with its BAR-domain-mediated targeting of cargo to curved membranes, indicates a central role for PICK1 in receptor and transporter endocytosis and recycling.

\section{Roles of PICK1 in glutamate receptor function}

Disruption of the glutamate system has been implicated in the pathophysiology of bipolar I disorder and symptoms of schizophrenia [3,24-29]. Antagonists of NMDA glutamate receptors, such as phencyclidine and ketamine, induce psychotic signs and symptoms of schizophrenia, probably by increased glutamate release and activation of AMPA glutamate receptors [24,30]. Moreover, genetic studies indicate that NMDA, AMPA and kainate glutamate receptors are loci for schizophrenia [8,13]. The PDZ domain of PICK1 has been reported to interact with the C-terminal PDZ motifs of AMPA [31,32], kainate [33] and metabotropic [34-36] glutamate receptor subunits and subtypes. PICK1 regulates glutamate receptor phosphorylation by PKC and can control receptor clustering and synaptic expression [14-16,36-42]. Thus, PICK1 can regulate plasticity in the hippocampus and cerebellum, thus having a role in learning and memory [14-16,36-42]. The mutated PDZ domain of PICK1 in schizophrenia patients [11,12] might lead to the altered surface expression and/or trafficking of glutamate receptors and could increase susceptibility for schizophrenia.

\section{PICK1 regulation of dopamine transporters}

Monoamine transporters are located at perisynaptic sites and recycle monoamines via uptake and vesicle storage. In monoamine-transporter-knockout mice, the level of monoamines in intracellular stores and transmitter release are depleted [43]. Numerous pharmacological agents stimulate (e.g. amphetamine) or inhibit (e.g. cocaine) these transporters and induce hallucinogenic symptoms. They are also targeted by antidepressants and psychostimulants and are involved in psychiatric diseases [43]. The dopamine neurotransmitter system as a model for schizophrenia was developed based on pharmacological evidence that dopamine receptor agonists and antagonists trigger and reduce psychosis, respectively, and the suggestion that dopamine receptor polymorphisms are associated with the disease [44].

The PDZ domain of PICK1 also interacts with monoamine transporters of dopamine (DAT) and norepinephrine (NET), both of which have been associated with schizophrenia $[43,45]$. In dopamine-containing neurons, PICK1 co-localizes with DAT, and the expression of recombinant PICK1 results in DAT-PICK1 clusters that enhance dopamine uptake because of an increase in the number of plasma membrane DATs, probably through a PKCdependent mechanism [45]. Therefore, it seems plausible that the regulation of DAT surface expression via PICK1 provides another potential mechanism for the involvement of PICK1 dysfunction in schizophrenia. 


\section{Interaction of PICK1 with serine racemase}

Glutamate released from neurons activates AMPA receptors on astrocytes, which express serine racemase. This enzyme converts $\mathrm{L}$-serine to $\mathrm{D}$-serine, which is an endogenous ligand for the glycine site of NMDA receptors [46]. The treatment of schizophrenics with D-serine ameliorates some symptoms [47]. In addition, genes encoding the ${ }_{\mathrm{D}}$-serine-degrading

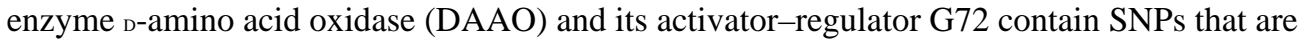
associated with schizophrenia [48-51]. Recent studies show that the PDZ domain of PICK1 interacts with serine racemase [12], which provides additional support for a role of PICK1 in schizophrenia.

\section{Pharmacological modulation of PICK1}

Together, the genetic reports, chromosomal location and protein interaction studies implicate a role for PICK1 in schizophrenia. Therefore, an important challenge is to determine whether PICK1 can be therapeutically targeted to provide treatment for this disorder. Little is known about how to regulate the BAR domain of PICK1. By contrast, numerous examples indicate that PDZ domain interactions can be competitively antagonized by synthetic blocking peptides (for review, see Ref. [52]) (Figure 1). These 'PDZ peptides' can be designed to block specific PDZ interactions and are effective both in vitro [33,38,53-55] and in vivo [56,57]. However, although they are useful research tools, PDZ peptides cannot readily penetrate cellular membranes, are rapidly degraded and have poor pharmacokinetic properties. These limitations of PDZ peptides have fuelled interest in generating low molecular weight drugs that block PDZ domain interactions. Indeed, crystal structure analysis and modeling approaches [37,58], in addition to chemical library screening, have provided drugs that block PDZ domain interactions [59-62]. These early compounds provide proof that low molecular weight compounds can block PDZ-proteinprotein interactions [60-62] and give hope that the PDZ domain of PICK1 can be modulated by drugs.

\section{Concluding remarks}

Outstanding questions that must be resolved to define unequivocally a role for PICK1 in schizophrenia include: (i) will studies using a larger number of patients confirm that PICK1 mutations are associated with an increased risk of schizophrenia? (ii) Do the currently reported SNPs in the PDZ domain of PICK1 alter its function and its interaction with all or just some of its associated proteins? (iii) Are SNPs in other regions of PICK1, for example its BAR domain, also associated with schizophrenia? (iv) Are other PICK1-interacting proteins also associated with schizophrenia? Overall, there are several possible avenues for future research aimed at modulating PICK1 PDZ interactions and/or modulating the levels of specific interacting partners with drugs. Obviously, a great deal of work must be carried out on each of these approaches to refine the methodology, define better the precise target sequences for enhanced selectivity and design improved delivery mechanisms. Further work is also needed to determine which combinations of PICK1 interactions should be regulated and which of these interactions should be enhanced or inhibited for beneficial effects in schizophrenia.

We believe that PICK1 is an exciting target for potential pharmaceutical intervention and that the capability to manipulate PICK1 interactions will lead to a greater understanding of its putative role in neuronal function and dysfunction; this, in due course, could lead to a novel therapy for schizophrenia. 


\section{Glossary}

\section{AMPA receptor}

BAR domain

Disorganized

schizophrenics

Dopamine receptor

Ephrins

G72

GTPases

Neuregulin

NMDA receptor

Occipital cortex

Paranoia

PDZ domain

PICK1

Polymorphisms

SNP subtype of ionotropic transmembrane receptor for glutamate that mediates most of the fast synaptic transmission in the CNS.

crescent-shaped structure within proteins that is involved in membrane bending and tubulation.

characterized by agitated and purposeless behavior.

G-protein-coupled metabotropic receptors that can be excitatory or inhibitory to the postsynaptic neuron.

a family of protein ligands for ephrin receptor protein-tyrosine kinases that regulate axon guidance.

a protein that activates $\mathrm{D}$-serine oxidation by DAAO.

a large family of enzymes that bind to and hydrolyze GTP. They have important functions in many aspects of cell function, including signaling and protein trafficking.

a family of four structurally related growth factors that are highly expressed in the developing and adult brain.

subtype of ionotropic transmembrane glutamate receptor. Calcium flux through NMDA receptors has a crucial role in synaptic plasticity, which is a cellular mechanism for learning and memory. visual-processing region at the back of the mammalian brain. a psychotic disorder characterized by delusions of persecution. protein-binding module within proteins that consists of 80-90 amino acids that fold into six $\beta$-strands and two $a$-helices.

a single-PDZ-domain protein that mediates interaction with the $\mathrm{C}$ termini of several receptors, transporters, ion channels and kinases.

differences in DNA sequence among individuals. Genetic variations occurring in $>1 \%$ of a population would be considered useful polymorphisms for genetic linkage analysis.

DNA sequence variation at a single nucleotide. SNPs make up $90 \%$ of all human genetic variations.

\section{References}

1. Sadock, BJ.; Sadock, VA. Schizophrenia. In: Kaplan, HI.; Sadock, BJ., editors. Synopsis of Psychiatry. 9th edn. Lippincott Williams and Wilkins; 2003. p. 471-504.

2. Buchanan, RW.; Carpenter, WT, Jr. Schizophrenia. In: Sadock, BJ.; Sadock, VA., editors. Textbook of General Psychiatry. 8th edn. Vol. 1. Lippincott Williams and Wilkins; 2005. p. 1329-1558.

3. Harrison PJ, Weinberger DR. Schizophrenia genes, gene expression, and neuropathology: on the matter of their convergence. Mol. Psychiatry. 2005; 10:40-68. [PubMed: 15263907]

4. Goff DC. Pharmacologic implications of neurobiological models of schizophrenia. Harv. Rev. Psychiatry. 2005; 13:352-359. [PubMed: 16373329]

5. Harrison PJ, Owen MJ. Genes for schizophrenia? Recent findings and their pathophysiological implications. Lancet. 2003; 361:417-419. [PubMed: 12573388]

6. Owen MJ, et al. Schizophrenia: genes at last? Trends Genet. 2005; 21:518-525. [PubMed: 16009449] 
7. Collier DA, Li T. The genetics of schizophrenia: glutamate not dopamine? Eur. J. Pharmacol. 2003; 480:177-184. [PubMed: 14623361]

8. Moises HW, et al. The glial growth factors deficiency and synaptic destabilization hypothesis of schizophrenia. BMC Psychiatry. 2002; 2:1-14. [PubMed: 11825340]

9. Staudinger J, et al. PICK1: a perinuclear binding protein and substrate for protein kinase $\mathrm{C}$ isolated by the yeast two-hybrid system. J. Cell Biol. 1995; 128:263-271. [PubMed: 7844141]

10. Staudinger J, et al. Specific interaction of the PDZ domain protein PICK1 with the COOH terminus of protein kinase C-a. J. Biol. Chem. 1997; 272:32019-32024. [PubMed: 9405395]

11. Hong CJ, et al. Association study of PICK1 rs3952 polymorphism and schizophrenia. Neuroreport. 2004; 15:1965-1967. [PubMed: 15305146]

12. Fujii K, et al. Serine racemase binds to PICK1: potential relevance to schizophrenia. Mol. Psychiatry. 2006; 11:150-157. [PubMed: 16314870]

13. Dracheva $S$, et al. mRNA expression of AMPA receptors and AMPA receptor binding proteins in the cerebral cortex of elderly schizophrenics. J. Neurosci. Res. 2005; 79:868-878. [PubMed: 15696539]

14. Dev KK. Making protein interactions druggable: targeting PDZ domains. Nat. Rev. Drug Discov. 2004; 3:1047-1056. [PubMed: 15573103]

15. Hanley JG, Henley JM. Picking out the details of cerebellar LTD. Neuron. 2006; 49:778-780. [PubMed: 16543122]

16. Collingridge GL, et al. Receptor trafficking and synaptic plasticity. Nat. Rev. Neurosci. 2004; 5:952-962. [PubMed: 15550950]

17. Peter BJ, et al. BAR domains as sensors of membrane curvature: the amphiphysin BAR structure. Science. 2004; 303:495-499. [PubMed: 14645856]

18. Habermann B. The BAR-domain family of proteins: a case of bending and binding? EMBO Rep. 2004; 5:250-255. [PubMed: 14993925]

19. Zimmerberg J, McLaughlin S. Membrane curvature: how BAR domains bend bilayers. Curr. Biol. 2004; 14:250-252.

20. Steinberg JP, et al. Targeted in vivo mutations of the AMPA receptor subunit GluR2 and its interacting protein PICK1 eliminate cerebellar long-term depression. Neuron. 2006; 49:845-860. [PubMed: 16543133]

21. Jin W, et al. Lipid binding regulates synaptic targeting of PICK1, AMPA receptor trafficking, and synaptic plasticity. J. Neurosci. 2006; 26:2380-2390. [PubMed: 16510715]

22. Hanley JG, Henley JM. PICK1 is a calcium-sensor for NMDA-induced AMPA receptor trafficking. EMBO J. 2005; 24:3266-3278. [PubMed: 16138078]

23. Lu W, Ziff EB. PICK1 interacts with ABP/GRIP to regulate AMPA receptor trafficking. Neuron. 2005; 47:407-421. [PubMed: 16055064]

24. Harrison PJ. The hippocampus in schizophrenia: a review of the neuropathological evidence and its pathophysiological implications. Psychopharmacology. 2004; 174:151-162. [PubMed: 15205886]

25. Owen MJ, et al. Schizophrenia: a genetic disorder of the synapse? BMJ. 2005; 330:158-159. [PubMed: 15661762]

26. Fallin MD, et al. Bipolar I disorder and schizophrenia: a 440-single-nucleotide polymorphism screen of 64 candidate genes among Ashkenazi Jewish case-parent trios. Am. J. Hum. Genet. 2005; 77:918-936. [PubMed: 16380905]

27. Tsai GC, Coyle JT. Glutamatergic mechanisms in schizophrenia. Annu. Rev. Pharmacol. Toxicol. 2002; 42:165-179. [PubMed: 11807169]

28. Scarr E, et al. Cortical glutamatergic markers in schizophrenia. Neuropsychopharmacology. 2005; 30:1521-1531. [PubMed: 15886719]

29. Moghaddam B. Bringing order to the glutamate chaos in schizophrenia. Neuron. 2003; 40:881884. [PubMed: 14659087]

30. Heresco-Levy U. N-methyl-d-aspartate (NMDA) receptor based treatment approaches in schizophrenia: the first decade. Int. J. Neuropsychopharmacol. 2000; 3:243-258. [PubMed: 11343602] 
31. Dev KK, et al. The protein kinase Ca binding protein PICK1 interacts with short but not long form alternative splice variants of AMPA receptor subunits. Neuropharmacology. 1999; 38:635-644. [PubMed: 10340301]

32. Xia J, et al. Clustering of AMPA receptors by the synaptic PDZ domain-containing protein PICK1. Neuron. 1999; 22:179-187. [PubMed: 10027300]

33. Hirbec $\mathrm{H}$, et al. Rapid and differential regulation of AMPA and kainate receptors at hippocampal mossy fibre synapses by PICK1 and GRIP. Neuron. 2003; 37:625-638. [PubMed: 12597860]

34. Boudin $\mathrm{H}$, et al. Presynaptic clustering of mGluR7a requires the PICK1 PDZ domain binding site. Neuron. 2000; 28:485-497. [PubMed: 11144358]

35. Dev KK, et al. PICK1 interacts with and regulates PKC phosphorylation of mGluR7. J. Neurosci. 2000; 20:7252-7257. [PubMed: 11007882]

36. Dev KK, et al. Regulation of mglu 7 receptors by proteins that interact with the intracellular Cterminus. Trends Pharmacol. Sci. 2001; 22:355-361. [PubMed: 11431030]

37. Perez JL, et al. PICK1 targets activated protein kinase Ca to AMPA receptor clusters in spines of hippocampal neurons and reduces surface levels of the AMPA-type glutamate receptor subunit 2. J. Neurosci. 2001; 21:5417-5428. [PubMed: 11466413]

38. Terashima A, et al. Regulation of synaptic strength and AMPA receptor subunit composition by PICK1. J. Neurosci. 2004; 24:5381-5390. [PubMed: 15190111]

39. Kim E, Sheng M. PDZ domain proteins of synapses. Nat. Rev. Neurosci. 2004; 5:771-781. [PubMed: 15378037]

40. Song I, Huganir RL. Regulation of AMPA receptors during synaptic plasticity. Trends Neurosci. 2002; 25:578-588. [PubMed: 12392933]

41. Barry MF, Ziff EB. Receptor trafficking and the plasticity of excitatory synapses. Curr. Opin. Neurobiol. 2002; 12:279-286. [PubMed: 12049934]

42. Xia J, et al. Cerebellar long-term depression requires PKC-regulated interactions between GluR2/3 and PDZ domain-containing proteins. Neuron. 2000; 28:499-510. [PubMed: 11144359]

43. Torres GE, et al. Plasma membrane monoamine transporters: structure, regulation and function. Nat. Rev. Neurosci. 2003; 4:13-25. [PubMed: 12511858]

44. Scharfetter J. Dopamine receptor polymorphisms and drug response in schizophrenia. Pharmacogenomics. 2001; 2:251-261. [PubMed: 11535113]

45. Torres GE, et al. Functional interaction between monoamine plasma membrane transporters and the synaptic PDZ domain-containing protein PICK1. Neuron. 2001; 30:121-134. [PubMed: 11343649]

46. Mothet J-P, et al. d-serine is an endogenous ligand for the glycine site of the N-methyl-d-aspartate receptor. Proc. Natl. Acad. Sci. U. S. A. 2000; 97:4926-4931. [PubMed: 10781100]

47. Tsai G, et al. d-serine added to antipsychotics for the treatment of schizophrenia. Biol. Psychiatry. 1998; 44:1081-1089. [PubMed: 9836012]

48. Schumacher J, et al. Examination of G72 and d-amino-acid oxidase as genetic risk factors for schizophrenia and bipolar affective disorder. Mol. Psychiatry. 2004; 9:203-207. [PubMed: 14966479]

49. Chumakov I, et al. Genetic and physiological data implicating the new human gene G72 and the gene for d-amino acid oxidase in schizophrenia. Proc. Natl. Acad. Sci. U. S. A. 2002; 99:1367513680. [PubMed: 12364586]

50. Hattori E, et al. Polymorphisms at the G72/G30 gene locus, on 13q33, are associated with bipolar disorder in two independent pedigree series. Am. J. Hum. Genet. 2003; 72:1131-1140. [PubMed: 12647258]

51. Chen YS, et al. Findings in an independent sample support an association between bipolar affective disorder and the G72/G30 locus on chromosome 13q33. Mol. Psychiatry. 2004; 9:87-92.

[PubMed: 14699445]

52. Kim E, Sheng M. PDZ domain proteins of synapses. Nat. Rev. Neurosci. 2004; 5:771-781.

[PubMed: 15378037] 
53. Daw MI, et al. PDZ proteins interacting with C-terminal GluR2/3 are involved in a PKC-dependent regulation of AMPA receptors at hippocampal synapses. Neuron. 2000; 28:873-886. [PubMed: 11163273]

54. Park Y, et al. Long-term depression of kainate receptor-mediated synaptic transmission. Neuron. 2006; 49:95-106. [PubMed: 16387642]

55. Sans N, et al. NMDA receptor trafficking through an interaction between PDZ proteins and the exocyst complex. Nat. Cell Biol. 2003; 5:520-530. [PubMed: 12738960]

56. Aarts M, et al. Treatment of ischemic brain damage by perturbing NMDA receptor-PSD-95 protein interactions. Science. 2002; 298:846-850. [PubMed: 12399596]

57. Garry EM, et al. Specific involvement in neuropathic pain of AMPA receptors and adapter proteins for the GluR2 subunit. Mol. Cell. Neurosci. 2003; 24:10-22. [PubMed: 14550765]

58. Madsen KL, et al. Molecular determinants for the complex binding specificity of the PDZ domain in PICK1. J. Biol. Chem. 2005; 280:20539-20548. [PubMed: 15774468]

59. Ferrer M, et al. A PDZ domain-based detection system for enzymatic assays. Anal. Biochem. 2002; 301:207-216. [PubMed: 11814291]

60. Fujii N, et al. A selective irreversible inhibitor targeting a PDZ protein interaction domain. J. Am. Chem. Soc. 2003; 125:12074-12075. [PubMed: 14518976]

61. Shan J, et al. Identification of a specific inhibitor of the Dishevelled PDZ domain. Biochemistry. 2005; 44:15495-15503. [PubMed: 16300398]

62. Joshi M, et al. Discovery of low-molecular-weight ligands for the AF6 PDZ domain. Angew. Chem. Int. Ed. Engl. 2006; 45:3790-3795. [PubMed: 16671149]

63. Svensson TH, et al. Mode of action of atypical neuroleptics in relation to the phencyclidine model of schizophrenia: role of 5- $\mathrm{HT}_{2}$ receptor and a 1-adrenoreceptor antagonism. J. Clin. Psychopharmacol. 1995; 15:11-18.

64. Bleich A, et al. The role of serotonin in schizophrenia. Schizophr. Bull. 1988; 14:297-315. [PubMed: 3059473]

65. Lewis DA, et al. Selective alterations in prefrontal cortical GABA neurotransmission in schizophrenia: a novel target for the treatment of working memory dysfunction. Psychopharmacology. 2004; 174:143-150. [PubMed: 15205885]

66. Petryshen TL, et al. Genetic investigation of chromosome $5 \mathrm{q} \mathrm{GABA}_{\mathrm{A}}$ receptor subunit genes in schizophrenia. Mol. Psychiatry. 2005; 10:1074-1088. [PubMed: 16172613]

67. Martin LF, et al. a-7 nicotinic receptor agonists: potential new candidates for the treatment of schizophrenia. Psychopharmacology. 2004; 174:54-64. [PubMed: 15205879]

68. Leonard S, et al. Association of promoter variants in the 7 nicotinic acetylcholine receptor subunit gene with an inhibitory deficit found in schizophrenia. Arch. Gen. Psychiatry. 2002; 59:10851096. [PubMed: 12470124]

69. Scarr E, et al. Increased levels of SNAP-25 and synaptophysin in the dorsolateral prefrontal cortex in bipolar I disorder. Bipolar Disord. 2006; 8:133-143. [PubMed: 16542183]

70. Tachikawa H, et al. Polymorphism of the $5^{\prime}$-upstream region of the human SNAP-25 gene: an association analysis with schizophrenia. Neuropsychobiology. 2001; 43:131-133. [PubMed: 11287790]

71. Young CE, et al. SNAP-25 deficit and hippocampal connectivity in schizophrenia. Cereb. Cortex. 1998; 8:261-268. [PubMed: 9617921]

72. Thompson PM, et al. Altered levels of the synaptosomal associated protein SNAP-25 in schizophrenia. Biol. Psychiatry. 1998; 43:239-243. [PubMed: 9513732]

73. Rantakallio $\mathrm{P}$, et al. Association between central nervous system infections during childhood and adult onset schizophrenia and other psychoses: a 28-year follow-up. Int. J. Epidemiol. 1997; 26:837-843. [PubMed: 9279617]

74. Excoffon KJ, et al. A role for the PDZ-binding domain of the coxsackie B virus and adenovirus receptor (CAR) in cell adhesion and growth. J. Cell Sci. 2004; 117:4401-4409. [PubMed: 15304526]

75. Gilmore JH, et al. Maternal infection regulates BDNF and NGF expression in fetal and neonatal brain and maternal-fetal unit of the rat. J. Neuroimmunol. 2003; 138:49-55. [PubMed: 12742653] 
76. Bai O, et al. Expression of brain-derived neurotrophic factor mRNA in rat hippocampus after treatment with antipsychotic drugs. J. Neurosci. Res. 2003; 71:127-131. [PubMed: 12478621]

77. Hong CJ, et al. An association study of a brain-derived neurotrophic factor Val66Met polymorphism and clozapine response of schizophrenic patients. Neurosci. Lett. 2003; 349:206208. [PubMed: 12951204]

78. Jourdi $\mathrm{H}$, et al. Brain-derived neurotrophic factor signal enhances and maintains the expression of AMPA receptor associated PDZ proteins in developing cortical neurons. Dev. Biol. 2003; 263:216-230. [PubMed: 14597197]

79. Brown AS, et al. Elevated maternal interleukin-8 levels and risk of schizophrenia in adult offspring. Am. J. Psychiatry. 2004; 161:889-895. [PubMed: 15121655]

80. Gilmore JH, et al. Prenatal infection and risk for schizophrenia: IL-1 $\beta$, IL-6, and TNFa inhibit cortical neuron dendrite development. Neuropsychopharmacology. 2004; 29:1221-1229. [PubMed: 15085088] 


\section{Box 1. Drug targets for schizophrenia}

\section{Pharmacology and genetics of schizophrenia}

Pharmacological evidence using modulators of glutamate-mediated, dopamine-mediated and 5-hydroxytryptamine (5-HT)-mediated neurotransmission has helped to develop models of schizophrenia for these receptor systems (Table I). Antipsychotics such as haloperidol, chlorpromazine (Largactil $\left.{ }^{\circledR}\right)$, clozapine (Clozaril $\left.{ }^{\circledR}\right)$ and risperidone (Risperdal ${ }^{\circledR}$ ) have pharmacology profiles that include dopamine and 5-HT receptor antagonism but might also include antagonist activity at adrenoceptors, acetylcholine receptors and histamine receptors. These antipsychotics reduce delusions and hallucinations but might induce extrapyramidal-motoric uncontrolled body movements (tardive dyskinesia, dystonias, akathisia and pseudo-parkinsonism) due to dopamine action in nigrostriatal pathways [1,2]. Genetic studies have helped to identify putative risk factors for schizophrenia (Table I). Chromosomal hotspots for schizophrenia have been suggested and the chromosomal locations of some genes implicated in schizophrenia include regulator of G-protein signaling (RGS) (1q21-q22), dystrobrevin binding-protein 1 (DTNBP1) (6p24-p22), neuregulin (NRG) (8p22-p21), ,-amino acid oxidase activator (DAOA) (13q32-q34) and catechol- $O$-methyl-transferase (COMT) (22q11-q22) [3-8].

PICK1-interacting proteins with strong links to schizophrenia

The three PICK1-interacting proteins for which there is strong evidence for roles in schizophrenia are: (i) glutamate (Glu) receptor subunits and subtypes (e.g. Glu receptor $^{2}$ AMPA subunit, $\mathrm{Glu}_{5}$ receptor kainate subunit and $\mathrm{mGlu}_{7}$ receptor metabotropic receptor); (ii) DAT; and (iii) serine racemase (SR) (Table I).

PICK1-interacting proteins with possible roles in schizophrenia

Proteins that interact with PICK1 and have putative roles in schizophrenia include: (i) neuregulin (NRG) and ErbB tyrosine kinase receptors (e.g. ErbB2/HER2), which regulate neurodevelopment, neuronal migration and differentiation, and synaptic plasticity; (ii) presynaptic-vesicle-docking proteins such as syndecan-interacting protein ( $\beta$-SNAP) and possibly N-ethylmaleimide-sensitive factor (NSF); (iii) Coxsackie and adenovirus receptor (CAR); and (iv) brain-derived neurotrophic factor (BDNF), which regulates PICK1 expression (Table I).

Proteins that interact with PICK1 but have no or weak evidence for roles in schizophrenia

These proteins include: (i) Eph tyrosine kinase receptor (e.g. EphB2) and ephrin ligands; (ii) brain $\mathrm{Na}^{+}$channel (e.g. $\mathrm{BNaC} 1$ ) and acid-sensitive ion channel (ASIC); (iii) prolactin-releasing peptide receptor (PrRP); (iv) tetradecanoyl phorbol ester-induced primary response sequence (TIS21); (v) ADP ribosylation factor (e.g. ARF1); (vi) kalirin7, a guanine-nucleotide-exchange factor; (vii) syntenin; (viii) homolog of Caenorhabditis elegans UNC5 (UNC5H); (ix) aquaporin-9; (x) anion exchanger-1; and (xi) neuroligin [14]. 


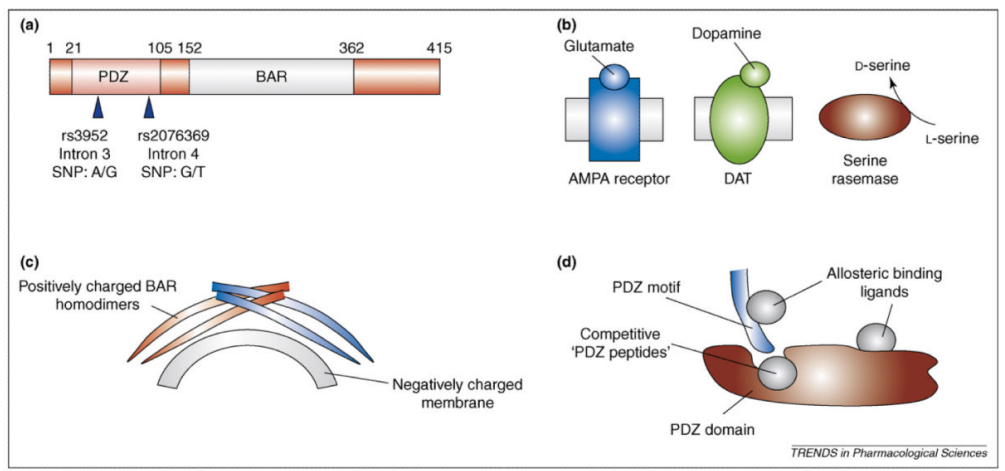

Figure 1.

PICK1-interacting proteins and regulation of PICK1 domains. (a) The structure of PICK1 and mutations linked to schizophrenia. Shown are the SNPs in the PDZ domain of PICK1 that are associated with schizophrenia. (b) Three proteins that interact with the PDZ domain of PICK1 and have a role in schizophrenia. The PDZ domain of PICK1 is unusual because it can bind to many types of PDZ motif (for review, see Ref. [14]). For example, it binds to PKCa via a type I PDZ motif $[9,10]$, whereas it binds to $\mathrm{Glu}_{2}$ receptor (an AMPA receptor subunit) via a type II PDZ motif [15,31,32]. Although PICK1 interacts with 20 different types of protein family [14], only the three proteins that have been associated with schizophrenia are shown: namely, AMPA receptors, DAT and serine racemase. PICK1 interacts with these proteins to regulate their function by PKC-mediated phosphorylation, synaptic clustering and/or membrane expression. (c) PICK1 harbors a BAR domain, in addition to its PDZ domain, that is involved in dimerization of PICK1 and interaction with glutamate-receptor-interacting protein (GRIP) [14]. GRIP is a PDZ-domain-containing protein that anchors AMPA receptors to the membrane [13,40,41]. The positively charged BAR homodimer of a-helical bundles is sufficient to support electrostatic forces with the negatively charged membrane and enable lipid-protein interactions. For example, a membrane containing $20 \%$ phosphatidylserine has a negative surface potential of approximately $-30 \mathrm{mV}$, attracting $\mathrm{K}^{+}$ions and clusters of basic protein residues (e.g. lysine). (d) Pharmacological approaches for regulating the PDZ domain interactions of PICK1. Competitive PDZ peptides match the sequences of PDZ motifs and fit into PDZ domains, thereby inhibiting the entry of endogenous PDZ motifs. PDZ peptides can be engineered to block specific interactions; for example, the PDZ peptide NVYGIESVKI, which is based on the PDZ-binding motif of the $\mathrm{Glu}_{2}$ receptor, blocks $\mathrm{Glu}_{2}$ receptor interaction with GRIP and PICK153. By contrast, the PDZ peptide NVYGIEEVKI, which is modeled on a phosphorylated $\mathrm{Glu}_{2}$ receptor mimic, blocks $\mathrm{Glu}_{2}$ receptor interaction with PICK1 but not GRIP53. Although no examples have been reported, the allosteric binding of drugs to PDZ motifs or PDZ domains could, in theory, alter the conformation of these interacting structures. This novel approach might be amenable to augment or attenuate PDZ interactions. 


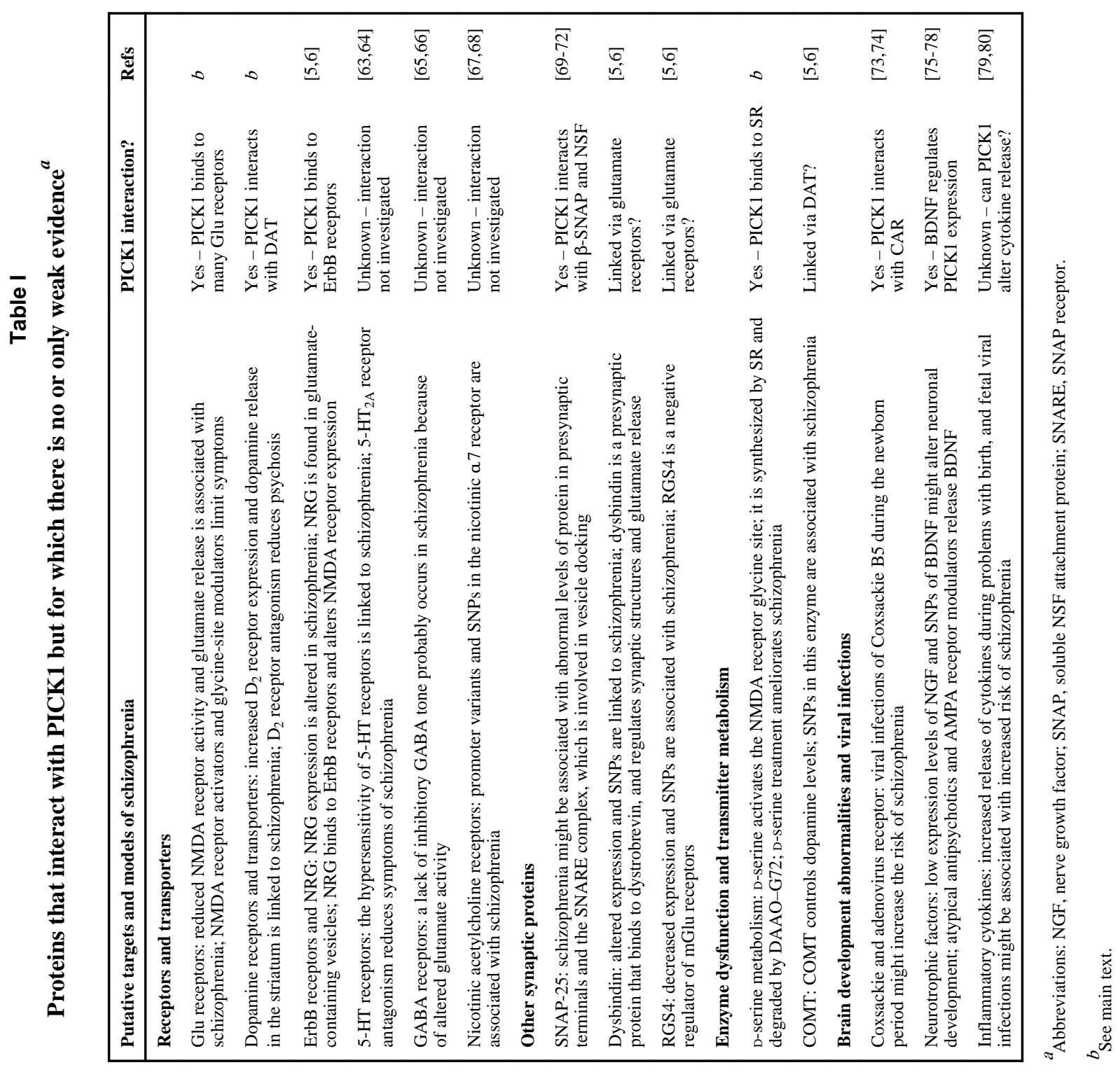

Trends Pharmacol Sci. Author manuscript; available in PMC 2012 March 28. 